\title{
HUBUNGAN KOMUNIKASI ORANG TUA-ANAK DENGAN STRES AKADEMIK MAHASISWA TAHUN PERTAMA PROGRAM STUDI SARJANA KEPERAWATAN DAN PROFESI NERS FK UNUD
}

\author{
Putu Utami Teja Saraswati ${ }^{1}$, Gusti Ayu Ary Antari², I Kadek Saputra ${ }^{3}$ \\ ${ }^{1}$ Mahasiswa Program Studi Sarjana Keperawatan Fakultas Kedokteran Universitas Udayana \\ ${ }^{2,3}$ Staff Dosen Program Studi Sarjana Keperawatan Fakultas Kedokteran Universitas Udayana \\ Alamat korespondensi: utamitejasaraswati@gmail.com
}

\begin{abstract}
Abstrak
Mahasiswa tahun pertama tergolong ke dalam usia remaja akhir yang mengalami ketidakstabilan emosi dan labil menghadapi masalah sehingga lebih mudah mengalami stres akademik. Stres akademik menjadi faktor terbesar yang mempengaruhi kinerja akademik mahasiswa. Dukungan keluarga berperan dalam menurunkan stres akademik. Landasan dasar tercapainya dukungan keluarga yang baik adalah komunikasi yang terciptasantara orang tua dan anak. Penelitian ini bertujuan mengetahui hubungan komunikasi orang tua-anak dengan stres akademik mahasiswa tahun pertama PSSKPN FK Universitas Udayana. Metode penelitian ini adalah korelatif dengan desain cross-sectional. Total sampling dilakukan pada 61 mahasiswa yang telah memenuhi kriteria inklusi dan eksklusi serta dianalisis menggunakan Pearson Product Moment. Berdasarkan penelitian yang telah dilakukan, didapatkan hasil bahwa terdapat hubungan negatif lemah yang bermakna antara komunikasi orang tua-anak dengan stres akademik $(\mathrm{r}=$ 0,363; pvalue $=0,004 ; \alpha=0,05)$. Semakin baik komunikasi orang-tua anak maka semakin rendah stres akademik yang dialami mahasiswa tahun pertama PSSKPN FK Universitas Udayana. Penelitian ini memberikan gambaran kepada mahasiswa, orang tua, dan institusi pendidikan untuk dapat memperhatikan mahasiswa terkait stres akademik dan dapat meningkatkan komunikasi antara orang tuaanak.
\end{abstract}

Kata kunci: Komunikasi Orang Tua-Anak, Stres Akademik, Mahasiswa Tahun Pertama

\begin{abstract}
First-year students belong to the age of late adolescents who experience emotional instability and are unstable facing problems, so they are more susceptible to academic stress. Academic stress is the biggest factor affecting student academic performance. Family support plays a role in reducing academic stress. The basic foundation for achieving good family support is communication created between parents and children. This research aims to seekkthe relationship of parent-child communication with academic stress students of first-year students School of Nursing Faculty of Medicine Udayana University. The method used in this study was correlative with a cross-sectional design. At total sampling conducted on 61 students who had met the inclusion and exclusion criteria and analyzed using Pearson Product Moment analysis. According to the study that has been done, it was founded that there was a weak negative relationship between parent-child communication with academic stress $(r=-0,363 ; p$-value $=0,004 ; \alpha=$ $0,05)$. The better parent-child communication, the lower the academic stress experienced by first-year students School of Nursing Faculty of Medicine Udayana University. This study provides an overview of students, parents, and educational institutions to be able to pay attention to students related to academic stress and can improve communication between parents and children.
\end{abstract}

Keywords: Parents-Children Communication, Academic Stress, First Year Students 


\section{PENDAHULUAN}

Stres merupakan sesuatu yang dapat dialami oleh setiap orang sepanjang kehidupannya (Purwati, 2012). Stres dapat dialami oleh siapa saja, dalam jangka waktu yang tidak sama, dengan kadar yang berbeda, dan akan berimplikasi negatif jika tidak ada solusi yang memadai (Sutjiato, Kandou \& Tucunan, 2015). Stres dapat menimpa siapa saja termasuk mahasiswa (Gadzella, Baloglu, Masten \& Wang, 2012).

Tolok ukur keberhasilan akademik mahasiswa pada umumnya dilihat dari prestasi akademik yang tergambar melalui Indeks Prestasi (IP), baik IP semester maupun IP kumulatif (Lailiana \& Handayani, 2017). Keberhasilan akademik mahasiswa juga ditandai dengan terselesaikannya kuliah tepat waktu. Keberhasilan akademik mahasiswa tidak hanya ditunjang oleh intelegensi yang tinggi, namun oleh kemauan belajar, dan terbebasnya mahasiswa dari stres akademik yang dapat mengganggu kegiatan belajar mengajar selama menjalani studi (Anidar, 2012). Pada jenjang mahasiswa, beratnya tingkat stres akademik berkaitan dengan tahun perkuliahan.

Augesti, dkk. (2015) dalam studinya menemukan bahwa tingkat stres akademik pada mahasiswa fakultas kedokteran tahun pertama lebih tinggi dibandingkan mahasiswa tingkat akhir. Stres yang sering, berat, dan berkepanjangan yang dialami oleh mahasiswa dapat menurunkan pencapaian akademik, mengganggu kemampuan untuk berpartisipasi dan berkontribusi dalam kehidupan kampus, bahkan dapat pula menyebabkan penyalahgunaan obat-obat terlarang dan cenderung akan merusak perilaku.
Beberapa studi melaporkan bahwa dukungan sosial berperan dalam menurunkan tingkat stres akademik. Dukungan sosial yang terpenting pada masa remaja yaitu berasal dari keluarga dalam hal ini orang tua (Ernawati \& Rusmawati, 2015). Dukungan keluarga merupakan dukungan sosial pertama yang diterima mahasiswa. Anggota keluarga dalam hal ini orang tua adalah orang yang berada di lingkungan paling dekat dan memiliki peluang besar untuk memberikan bantuan kepada mahasiswa (Putri, 2014). Landasan dasar tercapainya dukungan keluarga yang baik adalah komunikasi yang tercipta antara orang tua dan anak.

Studi pendahuluan yang dilakukan terhadap 20 mahasiswa tahun pertama Program Studi Sarjana Keperawatan dan Profesi Ners (PSSKPN) FK Universitas Udayana menunjukkan bahwa 10 dari 20 mahasiswa mengalami stres sedang, empat mahasiswa mengalami stres ringan dan enam mahasiswa tidak mengalami stres. Sejalan dengan hasil wawancara yang telah dilakukan terhadap lima mahasiswa tahun pertama PSSKPN FK Universitas Udayana, mengatakan bahwa mereka mengalami stres akademik di tahun pertamanya kuliah dikarenakan belum bisa mengatur waktu antara tugas, belajar, dan kegiatan non akademik. Selain itu mata kuliah yang tidak mudah dan jam perkuliahan yang padat karena menggunakan sistem pembelajaran dengan sistem blok juga menjadi pencetusnya. Berdasarkan uraian tersebut, maka penulis tertarik untuk meneliti hubungan komunikasi orang tua-anak dengan stres akademik mahasiswa tahun pertama PSSKPN FK Universitas Udayana. 


\section{METODE PENELITIAN}

Penelitian ini merupakan penelitiani deskripsif korelasional dengan rancangan cross-sectional di mana waktu pengukuran dan pengambilan data variabel independen dan dependen hanya satu kali pada satu saat. Penelitian dilaksanakan pada tanggal 22 dan 23 April 2019 dan dilakukan setelah jam perkuliahan berakhir.

Populasi pada penelitian ini merupakan seluruh mahasiswa tahun pertama PSSKPN FK Universitas Udayana. Teknik pengambilan sampel yang digunakan dalam penelitian ini adalah non-probability sampling dengan teknik total sampling sehingga jumlah sampel berjumlah 61 orang.

Kriteria inklusi dari penelitian ini yaitu mahasiswa tahun pertama PSSKPN FK Universitas Udayana yang masih berstatus aktif, bersedia menjadi responden dan menandatangani lembar persetujuan menjadi responden (informed consent), serta memiliki orang tua atau wali. Kriteria eksklusi dalam penelitian ini yaitu mahasiswa tahun pertama PSSKPN FK Universitas Udayana yang tidak bersedia menjadi responden dan tidak menandatangani lembar persetujuan menjadi responden (informed consent).

Data komunikasi orang tua-anak dan stres akademik mahasiswa diukur menggunakan kuesioner. Kuesioner komunikasi orang tua-anak disusun oleh Riskaponda (2014) yang terdiri dari 33 pernyataan sedangkan kuesioner stres akademik menggunakan Depression Anxiety and Stress Scale 42 (DASS 42) dan telah dikembangkan oleh Purwati (2012) berisi 60 pernyataan. Uji validitas dan reliabilitas telah dilakukan tanggal 26 Maret 2019 pada 30 mahasiswa tahun pertama Program
Studi Pendidikan Dokter FK Universitas Udayana.

Berdasarkan hasil uji tersebut, diketahui bahwa dari 33 item pernyataan terdapat item pernyataan yang tidak valid dengan nilai $r_{\text {hitung }}<0,374$ sehingga item pernyataan yang digunakan untuk mengukur komunikasi orang tua-anak adalah 25 item pernyataan dengan $r_{\text {hitung }} 0,423$ 0,824. Hasil uji kuesioner stres akademik diketahui bahwa dari 60 pernyataan, terdapat 30 pernyataan yang valid dengan nilai ritung 0,379-0,713.

Penelitian ini telah disetujui oleh Komisi Etik Penelitian FK UNUD/RSUP Sanglah yang telah melakukan telaah proposal. Peneliti sudah memberikan penjelasan tentang latar belakang, tujuan, manfaat, bahaya, kerahasiaan data, hal yang perlu dilakukan oleh responden, dan kesediaan menjadi responden penelitian. Sampel yang telah menyatakan kesediaannya untuk menjadi responden dalam penelitian diminta untuk menandatangani lembar persetujuan (informed consent). Responden diberikan waktu selama 30 menit untuk mengisi lembar kuesioner. Kuesioner yang telah diisii kemudian dikembalikan kepada peneliti dan peneliti memeriksa kelengkapan jawaban pada waktu yang sama.

Data variabel dari penelitian ini yaitu komunikasi orang tua-anak dan stres akademik. Hasil uji normalitas didapatkan bahwa kedua data terdistribusi normal menggunakan uji Kolmogorov-Smirnov sehingga uji statistik yang digunakan adalah Pearson Product Moment dengan tingkat kepercayaan $95 \%$.

\section{HASIL PENELITIAN}

Hasil analisis terhadap responden penelitian. 
Tabel 1.

Distribusi Frekuensi Berdasarkan Karakteristik Responden

\begin{tabular}{lcc}
\hline \multicolumn{1}{c}{ Variabel } & Frekuensi (n) & Persentase (\%) \\
\hline Usia & 22 & 36,1 \\
- 18 tahun & 39 & 63,9 \\
- 19 tahun & & \\
\hline Jenis Kelamin & 11 & 18 \\
- Laki-laki & 50 & 82 \\
- Perempuan & & \\
\hline Tempat Tinggal & 28 & 45,9 \\
- Bersama orang tua & 6 & 9,8 \\
- Bersama orang lain atau keluarga & & 44,3 \\
$\quad$ tanpa orang tua & 27 & \\
- Sendiri atau kost & & $18 \%$ \\
\hline
\end{tabular}

Sebagian besar responden berusia 19 tahun yaitu sebanyak 39 orang $(63,9 \%)$. Responden pada penelitian ini lebih banyak berjenis kelamin perempuan dengan persentase $82 \%$ dibandingkan responden berjenis kelamin laki-laki dengan persentase
18\%. Responden penelitian yang tinggal bersama orang tua sebanyak 28 responden $(45,9 \%)$, kemudian disusul oleh responden yang tinggal sendiri atau kost sebanyak 27 responden $(44,3 \%)$.

Tabel 2.

Hubungan Komunikasi Orang Tua-Anak dengan Stres Akademik

\begin{tabular}{ccc}
\hline Variabel & $\mathbf{r}$ & p value \\
\hline Komunikasi Orang Tua-Anak dengan Stres Akademik & $-0,363$ & 0,004
\end{tabular}

Hasil penelitian menunjukkan terdapat hubungan negatif lemah yang bermakna ntara komunikasi orang tua-anak dengan stres akademik $(\mathrm{r}=-0,363$; pvalue $=0,004 ; \alpha=0,05)$. Nilai koefisien korelasi adalah negatif $(\mathrm{r}=$ 0,363 ) yang berarti bahwa semakin baik komunikasi orang-tua maka semakin rendah stres akademik yang dialami oleh responden. Hasil pvalue kurang dari 0,05 mengindikasikan bahwa hipotesis alternatif (ha) diterima.

\section{PEMBAHASAN}

Hasil penelitia yang dilakukan pada mahasiswa tahun pertama PSSKPN FK Universitas Udayana menunjukkan bahwa terdapat hubungan yang lemah dan negatif antara komunikasi orang tua-anak dengan stres akademik. Hubungan negatif menunjukan bahwa semakin baik komunikasi antara orang tua dan anak maka semakin rendah stres akademik, sebaliknya semakin buruk komunikasi orang tua-anak maka semakin meningkat stres akademik yang dialami oleh mahasiswa.

Kategorisasi pada penelitian inimnjuga menunjukkan bahwa sebagian besar mahasiswa tahun pertama PSSKPN FK Universitas Udayana sudah melakukan komunikasi orang tua-anak dengan baik yaitu sebesar $62,3 \%$ atau sebanyak 38 mahasiswa. Namun stres akademik pada mahasiswa menunjukan bahwa 11 (18\%) mahasiswa normal dan 50 (82\%) mahasiswa mengalami stres akademik. Stres akademik tersebut dibagi menjadi stres akademik ringan sebanyak 35 $(57,4 \%)$, stres akademik sedang sebanyak 14 (23\%) mahasiswa dan stres 
berat sebanyak $1(1,6 \%)$ mahasiswa. Stres akademik mahasiswa tahun pertama PSSKPN FK Universitas Udayana dalam rentang perlu mendapatkan antisipasi karena secara umum $82 \%$ mengalami stres akademik.

Penelitian ini didukung oleh Mardiati, Hidayatullah, dan Aminoto (2018) yang menemukan bahwa tingkat stres pada remaja dalam hal ini remaja akhir yaitu mahasiswa tergolong tinggi. Pada kondisi stres, mahasiswa cenderung menjadi mudah marah dan tidak fokus, sehingga dapat mempengaruhi kemampuan dan orientasi terhadap proses pembelajaran yang diikuti. Hasilnya mahasiswa menjadi mudah pusing, penundaan penyelesaian tugas, dan mengalami gangguan tidur. Gunandar dan Utami (2017) menemukan bahwa dukungan sosial orang tua memberikan pengaruh terhadap penyesuaian diri mahasiswa tahun pertama yang merantau sehingga stres akademik yang dialami dapat berkurang.

Mahasiswa tahun pertama pada awal menempuh pendidikan di perguruan tinggi dihadapkan pada berbagai tantangan dan perubahan dalam hidup yang menyebabkan mereka memiliki derajat stres akademik yang lebih tinggi jika dibandingkan dengan mahasiswa tahun lainnya (Oktovia, Zulharman \& Devi, 2012). Stres akademik diartikan sebagai kondisi di mana mahasiswa tidak mampu untuk menerima beban pendidikan yang terlalu tinggi karena tuntutan orangk tua, kampus, dan suasana kampus yang tidak kondusif untuk belajar (Wijaya \& Naryoso, 2017).

Beberapa studi melaporkan bahwa dukungan sosial dalam hal ini orang tua berperan dalam menurunkan tingkat stres akademik. Komunikasi yang tercipta antara orang tuak dan anak adalah dasar tercapainya dukungan keluarga yang baik. Komunikasi orang tua dan anak juga merupakan pengisi kebutuhan anak yang mutlak akan interaksi. Apabila anak menghabiskan sebagian waktunya bersama orang tuanya dengan mampu menjaga keefektifan komunikasi, maka besar peluang bagi anak untuk dapat bersikap positif sehingga tidak akan mudah mengalami stres akademik.

\section{KESIMPULAN DAN SARAN}

Berdasarkan hasil penelitian diperoleh kesimpulan yaitu sebagian besar komunikasi orang tua-anak berada pada kategori baik. Stres akademik yang dialami sebagian besar mahasiswa berada pada kategori ringan. Terdapat hubungan negatif lemah yang bermakna antara komunikasi orang tua-anak dengan stres akademik yang berarti semakin baik komunikasi orang tuaanak maka semakin rendah stres akademik yang dialami mahasiswa tahun pertama PSSKPN FK Universitas Udayana.

Saran yang dapat diberikan adalah bagi mahasiswa dapat berbagi atau bertukar pikiran mengenai masalah-masalah yang dihadapi kepada orang tua sehingga dapat menekan terjadinya stres akademik pada dirinya. Bagi orang tua agar lebih meningkatkan hubungan dan komunikasi yang baik dengan anaknya. Bagi institusi pendidikan sebaiknya lebih memperhatikan mahasiswa pada saat berada di lingkungan kampus dan sebagai upaya preventif masalah kesehatan mental dapat dilakukan peningkatan fasilitas pembimbing akademik bagi mahasiswa. Bagi peneliti selanjutnya disarankan agar subjek penelitian dapat lebih bervariasi dengan melibatkan mahasiswa dari lebih banyak fakultas atau universitas agar 
data yang didapatkan lebih bermanfaat bagi banyak pihak.

\section{DAFTAR PUSTAKA}

Anidar, (2012). Peranpenasehat akademik terhadap kesuksesan mahasiswa di perguruan tinggi. Jurnal Al-Ta'lim, 1(3), 216-223. Diakses dari journal.tarbiyahiainib.ac.id

Augesti, G., Lisiswanti, R., Saputra, O., Nisa, K. (2015). Perbedaan tingkat stres antara mahasiswa tingkat awal dan tingkat akhir fakultas kedokteran universitas lampung. Journal Mahority, 4(4), 50-56. Diakses dari http://juke.kedokteran.unila.ac.id

Ernawati, ssL., \& Rusmawati, ffD. (2015). Dukungan sosial orang tua dan stres akademik pada siswa smk yang menggunakan kurikulum 2013. Jurnal Empati, 4(4), 26-31. Diakses dari https://ejournal3.undip.ac.id

Gadzella, B., Baloglu, M., Masten, W., \& Wang, Q. (2012). Evaluation of the student life-stressfsggg inventoryrevised. Journalk of Instructional Psychology, 39(2), 82-91.

Gunandar, M.S. \& Utami, M.S. (2017). Hubungan antara dukungan sosial orang tua dengan penyesuaian diri mahasiswa baru yang merantau. Gadjah Mada Journal of Psychology, 3(2), 98-109.

Lailiana, N.A., \& Handayani, A. (2017). Motivasit berprestasi ditinjau dari komitmen terhadap tugas pada mahasiswa. Elic, 89-96. Diakses dari jurnal.unissula.ac.id

Mardiati, I., Hidayatullah, F. Aminoto, C. (2018). Faktor eksternal tingkat stres mahasiswa keperawatan dalam adaptasi proses pembelajaran. Urecol, 172-181.

Oktovia, W., Zulharman \& Devi. R. (2012). Hubungan kecerdasan emosional dengan tingkat stres pada mahasiswa tahun pertama fakultas kedokteran universitas riau. (Skripsi, Universitas Riau).

Purwati, S.g (2012). Tingkat stres akademik pada mahasiswa reguler angkatan 2010 fakultas ilmu keperawatan Universitas Indonesia. (Skripsi, Universitas Indonesia). Diakses dari http://lib.ui.ac.id

Putri, D.L. (2014). Hubungan antara dukungan sosial oang tua dengan prokrastinasi akademik pada mahasiswa fakultas psikologi universitas kristen satya wacana salatiga. (Skripsi, Universitas
Kristen Satya Wacana). Diakses dari http://repository.uksw.edu

Sutjiato, M., Kandou, G., \& Tucunan, A. (2015). Hubungan faktor internal dan eksternal dengan tingkat stres pada mahasiswa fakultas kedokteran universitas sam ratulangi manado. JIKMU, 5(1), 30-42. Diakses dari https://ejournal.unsrat.ac.id

Wijaya, A., \& Naryoso. (2017). Komunikasi interpersonal lintas generasi untuk menghadapi strese akademik pada anak. Interaksigh Online, 18(2), 1-7. 